\title{
Sorption of Testosterone on Partially-Dispersed Soil Particles of Different Size Fractions: Methodology and Implications
}

Yong $\mathrm{Qi}^{\mathrm{a}}$ and Tian C. Zhang ${ }^{\mathrm{b}}$

${ }^{a}$ Post-doc research assistant and corresponding author, 136 PKI, email: yqi01 @ unomaha.edu; ${ }^{b}$ Professor, 205D PKI, Civil Engineering Dept., University of Nebraska-Lincoln, Omaha, NE 68182, USA.

Abstract. Sorption of hormones to soil particles of different size fractions (DSFs) has been studied to understand their fate and transport $(\mathrm{F} / \mathrm{T})$ in soils. Conventional studies fractionated the soil particles into DSFs by using the high speed stirring method and/or adding surfactants to fully

11 disperse the bulk soil. However, the natural processes (e.g., soil erosion, irrigation) often are

12 relatively mild, and many soil particles may be still in the aggregate form. In this study, a method

13 was developed for conducting the sorption test of a representative hormone (i.e., testosterone) to

14 bulk soils first and then analyzing the results against DSFs. Results indicated the particle size

15 distribution (PSD) of the two representative soils tested with partially-dispersed and fullydispersed methods was significantly different due to the attachment of clay particles on sand and

17 silt. Testosterone was sorbed mainly by the dominant aggregates even though they might have relatively lower sorption affinity than that of clays. However, the small particles $(<2000 \mathrm{~nm})$, even with $\sim 5 \%$ mass of the bulk soil, contributed more than $30 \%$ of sorbed testosterone in the "whole" soils. The partially-dispersed soil particles of DSFs should be used to understand the transport of hormone in runoff, because using the fully-dispersed soil particles will overestimate while the whole soil method will underestimate the transport potential. With the methodology developed in this study, the sorption tests will not compromise soil's original properties (e.g., aggregates) or the competition (e.g., sorption) among soil particles, and the contribution of DSFs

25 (particularly the partially-dispersed aggregates) to the sorption of the "whole" soil can be 26 determined.

Keywords: Sorption; Soil; Partially-dispersed; Particle size fraction; Testosterone 


\section{Introduction}

The increasing natural and synthetic steroidal hormones found in environments

31 worldwide have caused wide public concern because of their potential of adverse effects on

32 aquatic lives and human beings at very low concentrations (Kolpin et al., 2002; Orlando et al.,

33 2004; Martinovic et al., 2007; Young et al., 2014). Currently, one of the critical research areas is

34 to investigate the fate and transport $(\mathrm{F} / \mathrm{T})$ of hormones in the soil environment (Das et al., 2004;

35 Salvia et al., 2014), with sorption properties of hormones to soils of different textures and

36 organic contents being a major research focus. Soils with finer texture and higher organic content

37 were reported to have a higher sorption affinity (Lee et al., 2003; Casey et al., 2004; Ma 2009).

Soils contain a wide range of particles with different size fractions (DSFs). These

39 particles have different mobility during rainfall events (Mouri et al., 2014). Over $80 \%$ of the total

40 soil particles found in storm water runoff were less than $20 \mu \mathrm{m}$ (Randall, 1982; Furumai et al.,

41 2002). It has been reported that the sorption and desorption properties of pesticides (e.g., atrazine

42 and diuron) associated with soils exhibited significant particle-size dependence (Wang and

43 Keller 2008). A slight change in clay content in the sediment can greatly change the sediment's

44 potential for transporting chemicals sorbed on the solid phase (Foster et al., 1985). Therefore, it

45 is necessary to determine the sorption-desorption properties of hormones associated with soil

46 particles of DSFs. Qi et al. (2014) used wet-sieve-washing and repeated-sedimentation methods

47 to fractionate soils into five soil particles of DSFs and used each of the DSFs for conducting

48 sorption-desorption tests of testosterone. They found that the sorption and desorption properties

49 of soil particles of DSFs associated with hormones are very different; clay particles have

50 relatively high sorption capacity, mainly due to their high specific surface area. These previous

51 studies fractionated the soil particles into DSFs by using the high speed stirring method and/or 
52 adding surfactants (ASTM 2004), and then conducted the sorption tests with soil particles of

53 each size fraction independently (Wang and Keller 2008; Qi et al., 2014). These methods can be

54 used to determine the ultimate texture of the soil with respect to certain chemical or physical

55 properties and the sorption-desorption behavior of these soil particles of DSFs.

One concern is that these sorption tests may compromise the soil's original properties

57 (e.g., aggregates, attached organic matter) and the competition among soil particles of DSFs. It is

58 well-known that the fundamental difference between fully-dispersed and partially-dispersed soil

59 particles is very significant (Fig. 1). A soil aggregate is defined as a group of primary soil

60 particles that cohere to each other more strongly than to other surrounding particles (Le

61 Bissonnais 1996). Many soil aggregates are stable under the forces of erosion (Young 1980). In

62 nature, the dispersion processes (e.g., irrigation, soil erosion during storm events) often are

63 relatively mild, and these soil particles of DSFs are mixed together in the form of aggregates (i.e.,

64 partially-dispersed soil particles). Therefore, one should conduct the sorption tests with the 'bulk'

65 soil first, and then fractionate the soil into particles (including soil colloids) of DSFs using

66 partially-dispersed methods (e.g., no chemical, mild stirring). However, the existing knowledge

67 gap is: after the sorption test with the bulk soil, how to fractionate the soil particles of DSFs and then evaluate their contributions to sorption of hormones?

69 The goal of this study is to fill this knowledge gap. The specific objectives of this study

70 were to: 1) develop the procedures to conduct sorption test with bulk soil first, and then

71 fractionate soil particles into DSFs under series sedimentation and centrifugation conditions; 2)

72 compare the properties [e.g., total organic carbon (TOC), particle size distribution (PSD)] of

73 partially-dispersed and fully-dispersed soil particles of DSFs; and 3) investigate the sorption

74 distribution of testosterone among partially-dispersed soil particles of DSFs in the bulk soils. 


\section{Materials and Methods}

Figs. 2 and 3 shows the major procedures developed in this study. Details are as follows.

77 83 et al., 2000).

\subsection{Selected Hormones and Soils}

Testosterone was selected as the representative hormone because 1) it is a prototype for other synthetic androgenic hormones (Kanayama and Pope 2012); 2) little is known about the F/T of androgenic hormones (Casey et al., 2004); and 3) it was used previously (Qi et al., 2014; Qi and Zhang 2015a; Ma et al., 2015). In the present study, sorption tests were conducted with testosterone at environmentally relevant low concentration levels (20-150 ng/L) (Finlay-Moore

Two representative soils were selected to evaluate the effects of soil properties on methodology establishment and sorption properties of hormones; they were HAL (Haskell Agriculture Laboratory, Concord, NE, USA) soil and Iowa Black (IA, USA). These two soils were selected because they were sampled from the sites where the concentrated animal feeding operations (CAFOs) were nearby, and they were used in the previous studies (Ma et al., 2015; Qi et al., 2014). The HAL soil (Nora silty clay loam, fine-silty, mixed, mesic Udic Haplustolls) contains $0.95 \%$ total organic carbon (TOC). The total $\mathrm{Fe}, \mathrm{Cu}, \mathrm{Ca}, \mathrm{Mg}$ are 21, 4.7, 2131, 318 $\mathrm{mg} / \mathrm{kg}$, respectively. The cation exchange capacity (CEC) of HAL soil is $13.9 \mathrm{meq} / 100 \mathrm{~g}$. The Iowa Black (Dickinson sandy loam soil, coarse-loamy, mixed, superactive, mesic Typic Hapludolls) contains $0.68 \%$ TOC. The CEC of Iowa Black is 13.8 meq/100 g. No residual

4 testosterone was detected in the soil samples (Ma et al., 2015). After air drying and sieving with

5 a 2 -mm sieve to remove larger particles, the soils (called original soils) were ready for use. 
${ }^{14} \mathrm{C}$-labeled testosterone came from the American Radio Chemicals Society (St. Louis, MO, USA). Low activity stock solution $(=1 \mu \mathrm{g} / \mathrm{L}$, directly used in the experiment $)$ was made by

99 adding $1 \mu \mathrm{L}$ of high activity $(=50 \mu \mathrm{Ci})$ stock solution of ${ }^{14} \mathrm{C}$-labeled testosterone to $10 \mathrm{~mL}$ deionized $(\mathrm{DI})$ water (electrical resistivity $=18.2 \mathrm{M} \Omega \mathrm{cm}$ ). Unlabeled testosterone stock solution

$101(=10 \mu \mathrm{g} / \mathrm{mL})$ was made by dissolving $0.001 \mathrm{~g}$ testosterone into $100 \mathrm{~mL}$ methanol, and preserved 102 at $4{ }^{\circ} \mathrm{C}$ in a brown glass container under the dark condition. The concentration of methanol was 103 less than $1 \%$ by volume. Under this concentration, no effect of methanol on sorption of soils was 104 observed by other researchers (Wauchope and Koskinen 1983; Fan et al., 2007). $\mathrm{CaCl}_{2}(96 \%$ 105 purity) and $\mathrm{NaN}_{3}$ (99\% purity) were purchased from Fisher Scientific Inc.

\subsection{Fully-dispersed and Partially-dispersed Particle Size Distribution of Original Soils}

In this study, six diameter size ranges were studied for partially-dispersed soil particles

108 (Table 1): sand-sized aggregates (SDA = primary sand + large aggregates) $(2-0.075 \mathrm{~mm})$, silt-

109 sized aggregates $(\mathrm{STA}=$ primary silt + small aggregates $)(0.075-0.002 \mathrm{~mm})$, clay $1(2-0.9 \mu \mathrm{m})$,

110 Colloids \#1 (0.9-0.6 $\mu \mathrm{m})$, \#2 (0.6-0.4 $\mu \mathrm{m})$, and \#3 (0.4-0.2 $\mu \mathrm{m})$. For fully-dispersed ones,

111 corresponding size ranges of primary particles were investigated by Qi et al. (2014).

The PSD of HAL and Iowa Black soils were determined with both fully- and partially-

113 dispersed methods. The fully-dispersed (conventional method) PSD was evaluated according to

114 the standard methods (ASTM D422) (ASTM 2004) of both mechanical and hydrometer analyses.

115 While for the partially-dispersed PSD, the soils were evaluated with the similar procedure as

116 standard method except that $\left(\mathrm{NaPO}_{3}\right)_{6}$ was not added (Fig. 2), and the soil slurry was rotated (top

117 to bottom, one cycle per 5 second ( $360^{\circ} / 5$ s), NSI-34RH, Gearmoter, Bodine Electric Co.) for 24

118 hours instead of using high speed stirring as suggested by ADTM D422 (Fig. 2). The fully- 
119 dispersed and partially-dispersed clay mass distributions were measured with a particle size

120 analyzer (NanoBrook 90Plus/BI-MAS, Brookhaven Instrument Corp).

121 The mass distribution of the particles of six DSFs in the original soil was calculated by

122 integrating the area below the PSD curve of the bulk soil. After sorption tests (see Section 2.5),

123 the contribution of the particles of each size fraction to sorption of testosterone could be

124 calculated by multiplying the results of their sorption concentrations to their corresponding

125 weights in the original soil.

\section{$126 \quad 2.4 \quad$ Characterization of Partially-dispersed Soil Particles}

127 The SDA of HAL and Iowa Black soils was collected with the following steps: 1) place 5

$128 \mathrm{~g}$ of original soil with $250 \mathrm{~mL}$ DI water in each of plastic bottles; 2) put these bottles in a rotator

129 (top to bottom, $360^{\circ} / 5 \mathrm{~s}$ ) for 24 hours; 3 ) wet sieving these soil slurry with $200 \#(75 \mu \mathrm{m})$ sieve

130 with another $1000 \mathrm{~mL}$ DI water; 4) oven dry the residue (SDA) in the sieve at $105{ }^{\circ} \mathrm{C}$ for 24

131 hours; and 5) test the TOC of the SDA and original soils in a commercial lab (Mid-West lab,

132 Omaha, NE) with the standard method of ASTM D 5373.

133 The STA and clays from the original soils were fractionated with the sedimentation and 134 centrifugation methods. First, the original HAL (or Iowa Black) soil (1.0 g) was placed into each 135 of 24 plastic centrifuge tubes (\#220-3550-080, 50-mL, Evergreen Scientific, Los Angeles, CA, 136 USA). After adding $50 \mathrm{~mL}$ DI water, these 24 tubes were sealed with caps. All these tubes were 137 placed in a rotator (top to bottom, $360^{\circ} / 5 \mathrm{~s}$ ) for 24 hours. Then, four tubes were taken randomly

138 for analyzing the properties of STA: 1) each of the two tubes settled for 30 min and $240 \mathrm{~min}$ (Fig.

139 3), respectively; 2) the soil particle weight (SPW) of the supernatant of $30 \mathrm{~min}$ and $240 \mathrm{~min}$ 140 sedimentation was detected by a UV-spectrophotometer (GENESYS 10 UV, Thermo Electron 141 Co. Madison, WI, USA) at the wavelength of $288 \mathrm{~nm}$ (Qi and Zhang 2015b) of $\mathrm{MC}_{1}$ and $\mathrm{MC}_{2}$ : 


$$
W_{1-2}=\left(M C_{1}-M C_{2}\right) \times V_{c} \times 10^{-6}
$$

143 where $\mathrm{W}_{1-2}=$ weight of STA (between sedimentation conditions 1 and 2) $(\mathrm{g}) ; \mathrm{MC}_{1}$ and $\mathrm{MC}_{2}$

144 represent the total particle mass concentration of supernatant of separation conditions 1 and 2 $145(\mathrm{mg} / \mathrm{L})$, respectively; $\mathrm{V}_{\mathrm{c}}=$ volume of solution in centrifuge tube $(=50 \mathrm{~mL})$; and 3$)$ the TOC of 146 the supernatants of conditions 1 and 2 was tested with Fusion TOC machine (Model \#14-9600147 100, Teledyne Tekmar, Mason, OH, USA). The TOC of STA was calculated with Eq. 2:

$$
f_{O C}(\%)=\frac{T O C_{1}-T O C_{2}}{M C_{1}-M C_{2}} \times 100 \%
$$

149 where $f_{\mathrm{oc}}=$ soil particle organic carbon fraction $(\%) ; \mathrm{TOC}_{1}$ and $\mathrm{TOC}_{2}$ represent the concentration 150 of total organic carbon in the supernatant of conditions 1 and $2(\mathrm{mg} / \mathrm{L})$, respectively; $\mathrm{MC}_{1}$ and $151 \mathrm{MC}_{2}$ are the same as Eq. 1. The supernatant of condition 2 contains smaller and less weight of 152 particles than that of condition 1 due to longer sedimentation time.

153 For Clay 1 and Colloids \#1 to \#3, the centrifugation method was used instead of 154 sedimentation to accelerate the separation process for the other 20 tubes (each 4 tubes for 5 155 conditions). The operation conditions (e.g., centrifuge force and time) for HAL and Iowa black 156 soils are shown in Fig. 3 according to the previous study (Qi and Zhang 2015b). The TOC and 157 SPW of the supernatants collected under these separation conditions were detected with the same 158 methods as that of STA described above. Similarly, the weight and TOC of these clay particles 159 were calculated with Eq. 1 and Eq. 2. The principle of the methodology for evaluating the 160 property of the STA or clay particles was that the supernatant of condition 2 contains smaller 161 particles and less weight of particles than that of condition 1 due to the stronger centrifugal force 162 and/or longer centrifugal/sedimentation time. Therefore, the properties (e.g., TOC, weight, 163 sorption concentration) of particles of interest between conditions 1 and 2 could be calculated 
164 based on the properties' difference of the corresponding supernatants (Detailed calculation

165 examples are shown in Section 3.2 below).

\subsection{Sorption Tests with Original Soil and Analysis of Sorption Properties of DSFs}

Fig. 3 shows the procedure of how to fractionate the soil particles of DSFs and then evaluate their hormone sorption concentration after the sorption tests of the bulk soil

169 (collectively). All sorption tests described below were conducted with triplicates at room 170 temperature $\left(23 \pm 1^{\circ} \mathrm{C}\right)$. Original HAL (or Iowa black) soil (1.0 g) was placed into each of 50-

$171 \mathrm{~mL}$ glass centrifuge tubes (Corning Screw Thread Finish, Fisher Scientific). Then, $5 \mathrm{~mL}$ of

$172 \mathrm{CaCl}_{2}$ stock solution $(0.1 \mathrm{M})$ and $5 \mathrm{~mL} \mathrm{NaN}_{3}(2.0 \mathrm{~g} / \mathrm{L})$ were added to reach $0.01 \mathrm{M} \mathrm{CaCl}_{2}$ (for

173 controlling the ion strength) (Casey et al., 2004) and $200 \mathrm{mg} / \mathrm{L} \mathrm{NaN}_{3}$ (for eliminating the

174 microbial influence). Previous studies showed the $\mathrm{NaN}_{3}$ could be used to eliminate the microbial 175 influence on the study of hormone sorption to soils, and no influence had been reported (Kozarek 176 et al., 2008; Li et al., 2013). Three centrifuge tubes with the same situation of solution and soil

177 without testosterone were treated as blank. 100, 200, 350, 500, $750 \mu \mathrm{L}$ low stock ${ }^{14} \mathrm{C}$ labeled 178 testosterone were added to the corresponding tubes to reach initial testosterone concentration of $17920,40,70,100,150 \mathrm{ng} / \mathrm{L}$, respectively. Then, a corresponding volume of DI water was added 180 into each tube to reach $50 \mathrm{~mL}$ solution. All these tubes were rotated in the rotator (top to bottom, $181360^{\circ} / 5 \mathrm{~s}$ ) for 24 hours to reach sorption equilibrium (Ma et al., 2015). Then, the centrifuge tubes 182 with each initial hormone concentration were then settled or centrifuged with the selected 183 separation conditions (Fig. 3) to allow the particles with desired and smaller diameters to be left 184 in the supernatant. Then, $500 \mu \mathrm{L}$ supernatant (including particles of interest and smaller ones) 185 from the centrifuge tube was pipetted into a $20-\mathrm{mL}$ counting vial (Wheaton Millville, New 186 Jersey, USA) with $10 \mathrm{~mL}$ cocktail (Perkin Elmer, Waltham, MA, USA). The radioactivity of the 
sample was measured with 2500 TR liquid Scintillation Counter (Packard, Downers Grove, IL,

188 USA), and the hormone concentration was determined.

190 and soil particles of each diameter size range were determined based on mass balance as shown

191 in Fig. 3. Similarly, the testosterone concentration difference of the two supernatants obtained

192 from the two selected groups of separation conditions is due to the testosterone sorbed by the

193 particles, which would settle down due to stronger centrifugal force and/or longer

194 centrifuge/sedimentation time. Combining with the weight of particles calculated above (Eq. 1),

195 the sorbed concentration of testosterone to the soil particles of each size fraction (except SDA;

196 see Fig. 3) can be calculated:

$$
S=\frac{C_{1}-C_{2}}{M C_{1}-M C_{2}} \times 10^{3}
$$

198 where $\mathrm{S}=$ sorbed concentration of testosterone to soil particles of the diameter range between

199 separation conditions 1 and $2(\mathrm{ng} / \mathrm{g}) ; \mathrm{C}_{1}$ and $\mathrm{C}_{2}$ represent the testosterone concentration of

200 supernatant (including both dissolved phase in the liquid and residual hormone in suspended

201 particles) of separation conditions 1 and 2 (ng/L), respectively. $\mathrm{MC}_{1}$ and $\mathrm{MC}_{2}$ are the same as Eq.

202 1. The sorption concentration of SDA was calculated based on mass balance by submitting all

203 the sorption of STA, clay 1, and Colloids \#1 to 3 from the sorption mass of original soil ( $\mathrm{S}_{\mathrm{SDA}}$ of 204 Fig. 3).

205 For the sorption isotherm of testosterone to soil particles of each size fraction, the linear 206 model was used to fit the sorption data in order to compare with the previous studies (Lee et al., 207 2003; Qi et al., 2014; Ma et al., 2015):

$$
S=K_{d} C
$$


209 where $\mathrm{S}$ is the same as Eq. 3; $\mathrm{K}_{\mathrm{d}}=$ linear sorption coefficient (liquid and solid phase partition

210 coefficient) $(\mathrm{L} / \mathrm{kg})$; and $\mathrm{C}=$ equilibrium aqueous testosterone concentration (ng/L). The

211 normalized sorption coefficient for organic carbon $\left(\mathrm{K}_{\mathrm{oc}}\right)$ was calculated as:

$$
K_{o c}=\frac{K_{d}}{f_{o c}}
$$

213 where $f_{\mathrm{oc}}=$ soil particles' organic carbon fraction $(\%)$.

\section{$214 \quad 2.6 \quad$ Other Analytical Methods}

The TOC fractions of SDA and bulk soils were determined in a commercial lab (Mid-

216 West lab, Omaha, NE) with the standard method of ASTM D 5373. The PSD of supernatant was

217 analyzed with particle size analyzer (NanoBrook 90Plus/BI-MAS, Brookhaven Instrument Corp).

218 In order to eliminate the influence of testosterone sorbed to Teflon caps and glass tubes,

219 centrifuge tubes $(n=3)$ with the same amount of testosterone and solution without soil particles

220 were used as control. All the radioactivity detections were based on three blank samples (without

221 hormone) of centrifuge tubes that had the same situation (e.g., $\mathrm{CaCl}_{2}$ and $\mathrm{NaN}_{3}$ concentration,

222 soil-water ratio) as testing tubes. A microscope (LR33310Mod E, Fisher Scientific, Micro

223 Master Inc.) was used to check the diameter size of SDA and STA.

\section{$2253 \quad$ Results and Discussion}

226 3.1 Weight-based Particle Size Distribution of the Bulk Soils

The PSD tested with fully-dispersed and partially-dispersed methods are significantly

228 different. The percentage of clay particles tested with the partially-dispersed method (5.9\% for

229 HAL soil in Fig. 4a and 4.9\% for Iowa Black soil in Fig. 5a) is much lower than that with the

230 fully-dispersed method (44.6\% for HAL soil in Fig. 4a and 23.4\% for Iowa Black soil in Fig. 5a). 
231 Most of the clay particles are associated with the SDA (Figs. 4c \& 5c) and STA (Figs. 4d \& 5d)

232 under the partially-dispersed condition. For HAL soil, the STA percentage is $85.95 \%$ for

233 partially-dispersed soil, while that of silt is $49.52 \%$ for fully-dispersed soil (Fig. 4a). Therefore,

234 using the ASTM fully-dispersion methods [i.e., adding sodium hexametaphosphate $\left(\mathrm{NaPO}_{3}\right)_{6}$,

235 high-speed stirring] would definitely separate clay from silt particles, which otherwise would be

236 associated with silt to form STA (Fig. 4d). Similarly, for Iowa Black soil, the percentage of SDA

237 obtained from the partially-dispersed method is $74.19 \%$ (Fig. 5a), while that of sand obtained

238 from the fully-dispersed methods is 65\% (Fig. 5a). Moreover, the PSD of HAL and Iowa Black

239 soils are different (Fig. 4a and Fig. 5a): Iowa Black soil has more sand, and thus, more SDA,

240 while HAL soil has more silt and thus, more STA. In addition, the discrepancy between partially-

241 dispersed and fully-dispersed PSD of HAL soil is larger than that of Iowa Black soil, indicating

242 that the adhesion strength between the particles of HAL soil is much stronger than that of Iowa

243 Black soil. These results indicate that the new dispersion method (i.e., rotating the mixture of soil

244 and water without high speed stirring or adding surfactant) would mainly disperse the soils into

245 soil aggregates of DSFs rather than into primary particles.

$246 \quad 3.2 \quad$ Total Organic Carbon

247 For STA, clay 1 and Colloids \#1 to \#3, the TOC fractions were determined with Eqs. 1

248 and 2. Take the weight of HAL Colloid \#1 as an example, $\mathrm{MC}_{1}=386.1 \mathrm{mg} / \mathrm{L}$ for the supernatant

249 with an effective diameter size of $900 \mathrm{~nm}$ at $500 \mathrm{rpm}$ and $5 \mathrm{~min}$ (condition 1 ), $\mathrm{MC}_{2}=98.3 \mathrm{mg} / \mathrm{L}$

250 for that of $600 \mathrm{~nm}$ at $2000 \mathrm{rpm}$ and $5 \mathrm{~min}$ (condition 2), the difference of $\mathrm{MC}_{1}$ and $\mathrm{MC}_{2}$ is

251 caused by the settled colloids between $600-900 \mathrm{~nm}$ due to a stronger centrifugal force. The

252 weight of analyzed soil colloids between $600-900 \mathrm{~nm}$ is $\mathrm{W}_{1-2}=\left(\mathrm{MC}_{1}-\mathrm{MC}_{2}\right) \times 50 \mathrm{~mL}=(386.1-$

253 98.3) $\mathrm{mg} / \mathrm{L}$ x $0.05 \mathrm{~L}=14.39 \mathrm{mg}$. Similarly, $\mathrm{TOC}_{1}$ and $\mathrm{TOC}_{2}$ represent the concentration of TOC 
254 in the supernatant of conditions 1 and $2(\mathrm{mg} / \mathrm{L})$, respectively. Therefore, the $f_{\text {oc }}$ of these particles 255 can be calculated with Eq. 2.

256 As shown in Table 1, for HAL soil, the $f_{\text {oc }}$ of SDA and STA are $0.57 \%$ and $0.60 \%$, 257 respectively, which is much higher than that of the $f_{\text {oc }}$ of primary sand $(0.12 \%)$ and silt $(0.19 \%)$

258 as reported by Qi et al. (2014). This is because the corresponding aggregates have a higher TOC 259 content. The TOC distribution among particles of each size fraction could be calculated by 260 multiplying their TOC concentration (mg/g) (Table 1) with the corresponding weight $(\mathrm{g})$

261 distribution (Figs. 4 \& 5). For HAL soil, STA has the highest TOC distribution (51\%) among the 262 partially-dispersed soil particles of DSFs (Table 4 and Fig. 6). While for Iowa Black soil, Colloid 263 \#1 has the highest TOC distribution (26.9\%) among the DSFs (Fig. 6). These results are

264 important as TOC is one of the most important parameters to evaluate the $\mathrm{F} / \mathrm{T}$ of hormones in 265 soils. It was reported that the sorption behavior of $17 \alpha$-ethinylestradiol (EE2) to soils depended 266 greatly on the soil organic matter content and characteristics (Lima et al., 2012). Qi and Zhang 267 (2015a) studied the influence of humic acid on the sorption of testosterone to soil particles; they 268 found that the sorption capacity of soil particles increased significantly when the humic acid was 269 added. Furthermore, the weight and TOC results indicate that it is feasible to use sedimentation 270 and centrifugation methods to fractionate soil particles of DSFs with their properties being 271 successfully evaluated.

\section{$272 \quad 3.3 \quad$ Sorption Isotherm}

The $\mathrm{K}_{\mathrm{d}}$ value can be used to represent the sorption affinity of micro-pollutants to soil 274 particles (Conkle et al., 2010). $\mathrm{K}_{\mathrm{d}}$ is $79.9 \mathrm{~L} / \mathrm{kg}$ for the HAL bulk soil and $36.7 \mathrm{~L} / \mathrm{kg}$ for Iowa 275 Black bulk soil (Table 1), which are the lumped result of all soil particles (i.e., SDA, STA, Clay 276 1, Colloids \#1 to \#3). For HAL soil, the $\mathrm{K}_{\mathrm{d}}$ of SDA, STA and Clay 1 are 47.2, 63.5 and 189.4 
$277 \mathrm{~L} / \mathrm{kg}$, respectively (Table 1) when the sorption tests are conducted collectively. However, the $\mathrm{K}_{\mathrm{d}}$ 278 values of primary sand, silt and clay were $16.4,60.1$ and $87.8 \mathrm{~L} / \mathrm{kg}$, respectively when the 279 sorption tests were conducted with individually fully-dispersed soil particle fractions (Qi and 280 Zhang 2015a). Therefore, due to the attachment of clay and silt particles to sand particles (Fig. 281 4c), SDA has much higher sorption affinity than that of primary sand. For STA of HAL soil, the 282 sorption affinity is only slightly higher than that of primary silt; this might be because when the 283 sorption tests were conducted collectively, the clay particles, which have stronger sorption 284 affinity, competed with STA to sorb testosterone. On the contrary, the $\mathrm{K}_{\mathrm{d}}$ of clay particles is 285 much higher in collective situation $(=189.4 \mathrm{~L} / \mathrm{kg})$ than that of primary clay $(=87.8 \mathrm{~L} / \mathrm{kg})($ i.e., 286 when the sorption tests were conducted with fully-dispersed clay particles), which might be 287 caused from the reserved organic matter in the partially-dispersed clay particles. Normalizing TOC of these particles would show how organic matter would affect the 289 sorption affinity of testosterone to the partially-dispersed soil particles. The Log $\mathrm{K}_{\mathrm{oc}}$ (calculated 290 by Eq. 5) are 3.30 to 4.02 for HAL soil particles and 2.84 to 3.98 for Iowa Black (Table 1). The 291 results indicated that smaller soil particles have higher organic matter content, and thus, have a 292 larger sorption affinity.

$2933.4 \quad$ Sorption distribution of testosterone among soil particles of DSFs

294 Based on mass balance, the sorption distribution of testosterone among soil particles of 295 each size fraction was calculated by multiplying their sorption concentration (ng/g) (Fig. 7) and 296 their weight (g) distribution in the original soil (Figs. 4 \& 5). For HAL soil, at the initial 297 testosterone concentration of $150 \mathrm{ng} / \mathrm{L}$, the STA contributed $~ 73 \%$ of the testosterone sorbed by 298 all of the particles together (Table 2). When the initial concentration was $20 \mathrm{ng} / \mathrm{L}$, the STA only 299 contributed $\sim 39 \%$ (Table 2). While for clay 1, the contributions were $13.42 \%$ and $7.79 \%$ at the 
300 initial testosterone concentration of 20 and $150 \mathrm{ng} / \mathrm{L}$, respectively. This might be because the

301 smaller particles had higher sorption affinity than that of bigger ones (Fig. 7). When the

302 testosterone concentration was low, the bigger particles could not compete with the smaller ones,

303 leading to a relatively low sorption contribution. When the testosterone concentration was higher,

304 a large portion of the strong sorption sites of the smaller particles might be fulfilled, and thus, the

305 sorption contribution of STA and SDA became relatively larger.

306 As shown in Table 2, for HAL soil, the average sorption contribution is 63.13\% for STA,

307 and 10.2, 14.1, 6.1 and 1.3\% for Clay \#1, Colloids \#1, \#2, and \#3, respectively. Even though it

308 has a relatively low sorption affinity $\left(\mathrm{K}_{\mathrm{d}}\right)$, STA still sorbed most of the testosterone due to its

309 high percentage of mass (Fig. 4a). On the other hand, even though the total mass of clays was

$3105.94 \%$ (Fig. 4b), clay sorbed more than $30 \%$ of the testosterone sorbed by all of the particles

311 (Table 2). For sandy loam Iowa Black soil, the SDA contributed 41.94\% (Table 2) of the total

312 sorbed testosterone even though its mass percentage was $74.2 \%$ (Fig. 5a). Similar as the clay of

313 HAL soil, even though the mass added up of clay was $4.9 \%$ (Fig. 5b), 34\% of sorbed

314 testosterone were contributed by clays (Table 2$)$. Therefore, the small particles $(<2000 \mathrm{~nm})$ with

315 a higher sorption affinity will play critical roles in determining the F/T of hormones in soils due

316 to their high sorption potential and mobility.

$317 \quad 3.5 \quad$ Analysis of Relative Error Based on Different Particles to Evaluate Testosterone

$318 \quad$ Transport Potential

319 Being lipophilic (log $\mathrm{K}_{\mathrm{ow}}$ being 2.6-4.0), most steroidal hormones are expected to be

320 sorbed on soils and/or organic matter and are unlikely to be very mobile (Lai et al., 2000;

321 Schiffer et al., 2004; Khanal et al., 2006). However, this conclusion cannot explain the frequent

322 detections of hormones in ground and surface water. For example, it was reported that 
323 reproductive hormones were found in approximately $40 \%$ of the 139 streams sampled across 30

324 states in the United States (Kolpin et al., 2002). Testosterone has been detected in the soils

325 sampled from $45 \mathrm{~m}$ below a dairy-farm wastewater lagoon (Shai et al., 2008). In the past, it was

326 believed that particles- or colloids-facilitated transport of hormones to surface water through

327 runoff and leachate is the major mechanism for the aforementioned phenomena. However, it is

328 unknown how much difference there will be if one estimates the transport of testosterone based

329 on fully-dispersed soil particles, partially-dispersed soil particles or whole soil.

330 To do a preliminary estimation, additional tests were conducted with a soil slab reactor

331 (Fig. S1 in Supplementary Materials) under one artificial rainfall event, and determined the mass

332 distribution of SDA, STA, Clay 1, Colloids \#1 to \#3 of partially-dispersed soils particles and that

333 of fully-dispersed ones in the soil slurry collected through runoff (Table S1). Based on the

334 combined results shown in Table S1 and Table 1, Table 3 is created, which indicates that if using

335 the results of partially-dispersed soil particles as the datum, the transport of testosterone by

336 surface runoff will be either overestimated (by the method based on fully-dispersed soil particles,

$337+80.55 \%$ ) or underestimated (by that based-on the whole soil, $-44.92 \%$ ). Therefore, the sorption

338 parameter of partially-dispersed soil particles should be used to study the F/T of hormones rather

339 than based on fully-dispersed soil particles or whole soil.

3403.6 Relative Contribution of TOC and Specific Surface Area to Hormone Sorption

341 Results of this study indicate that the sorption affinity of the soil particles was mainly

342 determined by the specific surface area and TOC content, which is consistent with previous

343 studies (Fan et al., 2007; Wang et al., 2008; Gineys et al., 2012; Li, et al., 2013; Qi et al., 2014).

344 Sarmah et al. (2008) conducted the sorption of 17ß-estradiol (E2) and 17 $\alpha$-ethynylestradiol (EE2)

345 on six selected soils with batch reactors. They found that the sorption capacity of the soil was 
346 attributed to the surface area; the sorption difference was attributed by the soil organic carbon

347 content. However, the contribution of these two factors to hormones' sorption capacity has not

348 been compared because of the inconsistency of the soil properties (e.g., different soil mineral

349 components). Because TOC and particles sizes are the two main factors of the particles studied

350 in this research, the contribution of the two factors to the sorption capacity of these particles is

351 compared with the following equation:

352

$$
W=\mathrm{aT}+\mathrm{bF}
$$

353 where $\mathrm{W}=$ sorption contribution of soil particles of each size fraction to the "whole" soil (\%,

354 Column 5 in Table 4). T and F = TOC and surface area contribution of soil particles of each size

355 fraction to the "whole" soils ( $\%$, Columns 3 and 4 of Table 4 , respectively). The a and b

356 parameters represent the contribution weighting factors of TOC and surface area, respectively,

357 with $a+b=1$. The regression of Eq. 6 with the HAL and Iowa Black data shown in Table 4 was

358 conducted with Matlab R 2003a. The results showed that a and b were 0.589 and 0.411 ,

359 respectively, with the $\mathrm{R}^{2}$ being 0.9795 for HAL soil, and were 0.373 and 0.562 , respectively,

360 with the $\mathrm{R}^{2}$ being 0.7318 for Iowa Black. Therefore, for these two soils, both TOC and surface

361 area of the soil particles determined their sorption contributions. For HAL soil, TOC weights

362 higher than surface area, while for Iowa Black soil, the surface area of the soil particles plays a

363 more important role in their sorption contributions, which might be because HAL soil is a silty

364 clay loam and has a higher organic matter content (Table 1).

\subsection{Discussion}

366 In the past, the testing materials used by most previous studies for interaction of soil and

367 micro-pollutants were either whole soils (Lee et al. 2003; Kim et al. 2007; D'Alessio et al. 2014)

368 or fully-dispersed soil particles (Wang and Keller 2008; Qi et al. 2014; Qi and Zhang 2015a). 
However, in the real world, the transport of micro-pollutants is not through the whole soil due to

370 the mobility differences among soil particles in DSFs; more often than not, bulk soils are

371 dispersed in a partially-dispersed way due to the mild dispersion strength in nature. In this study,

372 we used sedimentation and centrifugation methods to fractionate two representative soils into

373 partially-dispersed soil particles of six DSFs, and, for the first time, investigated the sorption

374 distribution of testosterone among these particles under their natural conditions (i.e., with all

375 particles and aggregates being mixed together). The results indicated that the PSD of the two

376 soils tested with fully-dispersed and partially-dispersed methods are significantly different,

377 which was attributed by the attachment of clay particles on the sand and silt particles.

378 Testosterone was sorbed mainly by the dominant aggregates even though they might have

379 relatively lower sorption affinity than that of clays. However, the small particles $(<2000 \mathrm{~nm})$,

380 even with $\sim 5 \%$ mass only, contributed more than $30 \%$ of the sorbed testosterone in the "whole"

381 soil, leading to a high potential to facilitate the transport of hormones to surface and ground

382 water due to their high mobility.

383 Results of this study indicate that many factors may affect the potential for particles of

384 DSFs to facilitate the transport of testosterone to water bodies, such as PSD, particles' sorption

385 affinity, their relationship and mobility related to other particles. When studying the transport of

386 hormone with the particle-facilitated mechanism, the results of the sorption distribution of

387 testosterone among partially-dispersed soil particles of DSFs can be used to understand the

388 transport of testosterone in the soil environments in a more realistic way. Therefore, this study

389 provides a new perspective and methodology to better understand the interaction of soils and

390 hormones in soils. However, one still cannot predict the F/T of hormones in soils even with the

391 information of hormones' distribution among soil particles of DSFs. Roberts et al. (2014) 
392 reported that, in order to model the F/T of a pollutant comprehensively, one needs to incorporate,

393 other than sorption parameters, solute transport with other mechanisms (e.g., advection,

394 dispersion) as well as the transformation of the pollutant, let alone the variety of rainfall events.

395 Therefore, this study is only one step forward toward understanding and predicting the F/T of

396 hormones in soils. In the future, a new framework concerning the effects of partially-dispersed

397 soil particles on the F/T of micro-pollutants should be set up with the corresponding procedure

398 being standardized. Further studies considering other parameters and processes are needed to

399 obtain comprehensive results.

400

4014 Conclusion

402 In light of the above analysis, the following conclusions could be made:

403 1) The PSD evaluated through partially-dispersed and fully-dispersed process is significantly

404 different for the two soils tested; Testosterone sorbed mainly to STA for HAL soil even

405 though STA has a relatively lower sorption affinity. However, the small particles $(<2000$

$406 \mathrm{~nm}$ ), even with only $\sim 5 \%$ mass, contributed $>30 \%$ of sorbed testosterone by the whole soil;

407 2) The procedure developed in this study can be used to fractionate the soil particles of DSFs

408 and then evaluate their contributions to sorption of hormones after the sorption test with the

409 bulk soil, without compromising soil's original properties (e.g., aggregates) or the

$410 \quad$ competition among soil particles and aggregates;

411 3) The partially-dispersed soil particles of DSFs should be used to understand the transport of

412 hormone in runoff because the fully-dispersed method will overestimate while the whole soil

413 method will underestimate the transport potential; and 
4) Both TOC content and surface area of the soil particles will affect particles' sorption contribution to the "whole" soil with the weight factors being different of different soils.

\section{Acknowledgements}

419 Bartelt-Hunt in the Civil Engineering Department of University of Nebraska-Lincoln (UNL) for 420 providing soil samples and technical support. The research was made possible through support 421 from the U.S. National Science Foundation (NSF Award \#:1067537).

\section{References}

424 ASTM (The American Society for Testing and Materials). 2004. Annual Book of ASTM Standards, ASTM, West Conshohocken, PA, United States.

426 Casey, F. X. M., Hakk, H., Simunek, J., Larsen, G. L. 2004. Fate and Transport of Testosterone in Agricultural Soils. Environ. Sci. Technol., 38(3), 790-798.

428 Conkle, J. L., Lattao, C., White, J. R., Cook, R. L. 2010. Competitive Sorption and Desorption Behavior for Three Fluoroquinolone Antibiotics in a Wastewater Treatment Wetland Soil. Chemosphere, 80(11), 1353-1359.

D'Alessio, M., Vasudevan, D., Lichwa, J., Mohanty, S. K., Ray, C. 2014. Fate and Transport of Selected Estrogen Compounds in Hawaii Soils: Effect of Soil Type and Macropores. J. Contam. Hydrol., 166, 1-10.

Das, B. S., Lee, L. S., Rao, P. S. C., Hultgren, R. P. 2004. Sorption and Degradation of Steroid Sci. Technol., 38(5), 1460-1470.

Di Stefano, C., and Ferro, V. 2002. Linking Clay Enrichment and Sediment Delivery Processes. Biosyst. Eng., 81(4), 465-479. and Testosterone in Agricultural Soils. Chemosphere, 67(5), 886-895. 
Finlay-Moore, O., Hartel, P. G., Cabrera, M. L. 2000. 17 Beta-Estradiol and Testosterone in Soil and Runoff from Grasslands Amended with Broiler Litter. J. Environ. Qual., 29(5), 1604-1611.

Foster, G. R., Young, R. A., Neibling, W. H. 1985. Sediment Composition for Nonpoint Source Pollution Analyses. Trans. ASAE, 28(1), 133-146.

Furumai, H., Balmer, H., Boller, M. 2002. Dynamic Behavior of Suspended Pollutants and Particle Size Distribution in Highway Runoff. Water Sci. Technol., 46(11-12), 413418.

Gineys, N., Giroud, B., Gineys, M., Vulliet, E. 2012. Retention of Selected Steroids on a SiltLoam Soil. J. Environ. Sci. Health Part A-Toxic/Hazard. Subst. Environ. Eng., 47(13), 2133-2140.

Kanayama, G., and Pope, H. G. 2012. Illicit use of Androgens and Other Hormones: Recent Advances. Curr Opin Endocrinol Diabetes Obes, 19(3), 211-219.

Khanal, S. K., Xie, B., Thompson, M. L., Sung, S., Ong, S. K., Van, L. J. 2006. Fate, Transport, and Biodegradation of Natural Estrogens in the Environment and Engineered Systems. Environ. Sci. Technol., 40(21), 6537-6546.

Kim, I. 1., Yu, Z. Q., Xia, B. H., Huang, W. L. 2007. Sorption of Male Hormones by Soils and Sediments. Environ. Toxicol. Chem., 26(2), 264-270.

Kolpin, D., Furlong, E., Meyer, M., Thurman, E., Zaugg, S., Barber, L., Buxton, H. 2002. Pharmaceuticals, Hormones, and Other Organic Wastewater Contaminants in US Streams, 1999-2000: A National Reconnaissance. Environ. Sci. Technol., 36(6), $1202-1211$.

Kozarek, J. L., Wolfe, M. L., Love, N. G., Knowlton, K. F. 2008. Sorption of Estrogen to Three Agricultural Soils from Virginia, USA. Trans. ASABE, 51(5), 1591-1597.

Lai, K. M., Johnson, K. L., Scrimshaw, M. D., Lester, J. N. 2000. Binding of Waterborne Steroid Estrogens to Solid Phases in River and Estuarine Systems. Environ. Sci. Technol., 34(18), 3890-3894.

Le Bissonnais, Y. 1996. Aggregate Stability and Assessment of Soil Crustability and Erodibility - I. Theory and Methodology. European Journal of Soil Science, 47(4), 425-437. 
Lee, L. S., Strock, T. J., Sarmah, A. K., Rao, P. S. C. 2003. Sorption and Dissipation of Testosterone, Estrogens, and their Primary Transformation Products in Soils and Sediment. Environ. Sci. Technol., 37(18), 4098-4105.

Li, J., Fu, J., Xiang, X., Wu, M., Liu, X. 2013. Kinetics, Equilibrium, and Mechanisms of Sorption and Desorption of 17 Alpha-Ethinyl Estradiol in Two Natural Soils and their Organic Fractions. Sci. Total Environ., 452(1), 404-410.

Lima, D. L. D., Schneider, R. J., Esteves, V. I. 2012. Sorption Behavior of EE2 on Soils Subjected to Different Long-Term Organic Amendments. Sci. Total Environ., 423, $120-124$.

Ma, R., Zhang, T. C., Bartelt-Hunt, S. L., Qi, Y., Kranz, B., Snow, D., Mader, T., Shapiro, C., Shelton, D. P., Donk, S. V., Tarkalson, D., Ensley, S. 2015. Influence of Soil Properties and Test Conditions on Sorption and Desorption of Testosterone. J. Environ. Eng., DOI: 10.1061/ (ASCE) EE.1943-7870.0000937, 04015006, 1-9.

Ma, R. 2009. Sorption and Desorption of Testosterone in Agricultural Soils. Master Thesis, Civil Engineering Department, University of Nebraska-Lincoln, 2009.

Martinovic, D., Hogarth, W. T., Jones, R. E., Sorensen, P. W. 2007. Environmental Estrogens Suppress Hormones, Behavior, and Reproductive Fitness in Male Fathead Minnows. Environ. Toxicol. Chem., 26(2), 271-278.

Mouri, G., Shinoda, S., Golosov, V., Chalov, S., Shiiba, M., Hori, T., Oki, T. 2014. Estimating the Collapse of Aggregated Fine Soil Structure in a Mountainous Forested Catchment. J. Environ. Manage., 138(1), 24-31.

Orlando, E., Kolok, A., Binzcik, G., Gates, J., Horton, M., Lambright, C., Gray, L., Soto, A., Guillette, L. 2004. Endocrine-Disrupting Effects of Cattle Feedlot Effluent on an Aquatic Sentinel Species, the Fathead Minnow. Environ. Health Perspect., 112(3), 353-358.

Qi, Y., and Zhang, T. C. 2015a. Sorption and Desorption of Testosterone at Environmentally relevant Levels: Effects of Aquatic Conditions and Soil Particle Size Fractions. J. Environ. Eng., DOI: 10.1061/(ASCE) EE. 1943-7870.0001001, 1-9.

Qi, Y., and Zhang, T. C. 2015b. A Centrifugation and Mass-Balance-Based Methodology for Studying Sorption Behavior of Soil Colloids of Different Size Fractions for MicroPollutants. J. Environ. Eng., under review. 
Qi, Y., Zhang, T. C., Ren, Y. Z. 2014. Testosterone Sorption and Desorption: Effects of Soil Particle Size. J. Hazard. Mater., 279(30), 493-501.

Randall, C.W. Stormwater Detention Ponds for Water Quality Control. 1982. In storm water 
Table 1. Parameters of bulk soil and partially-dispersed soil particles of six different size

533 fractions (DSFs) of HAL and Iowa Black soils.

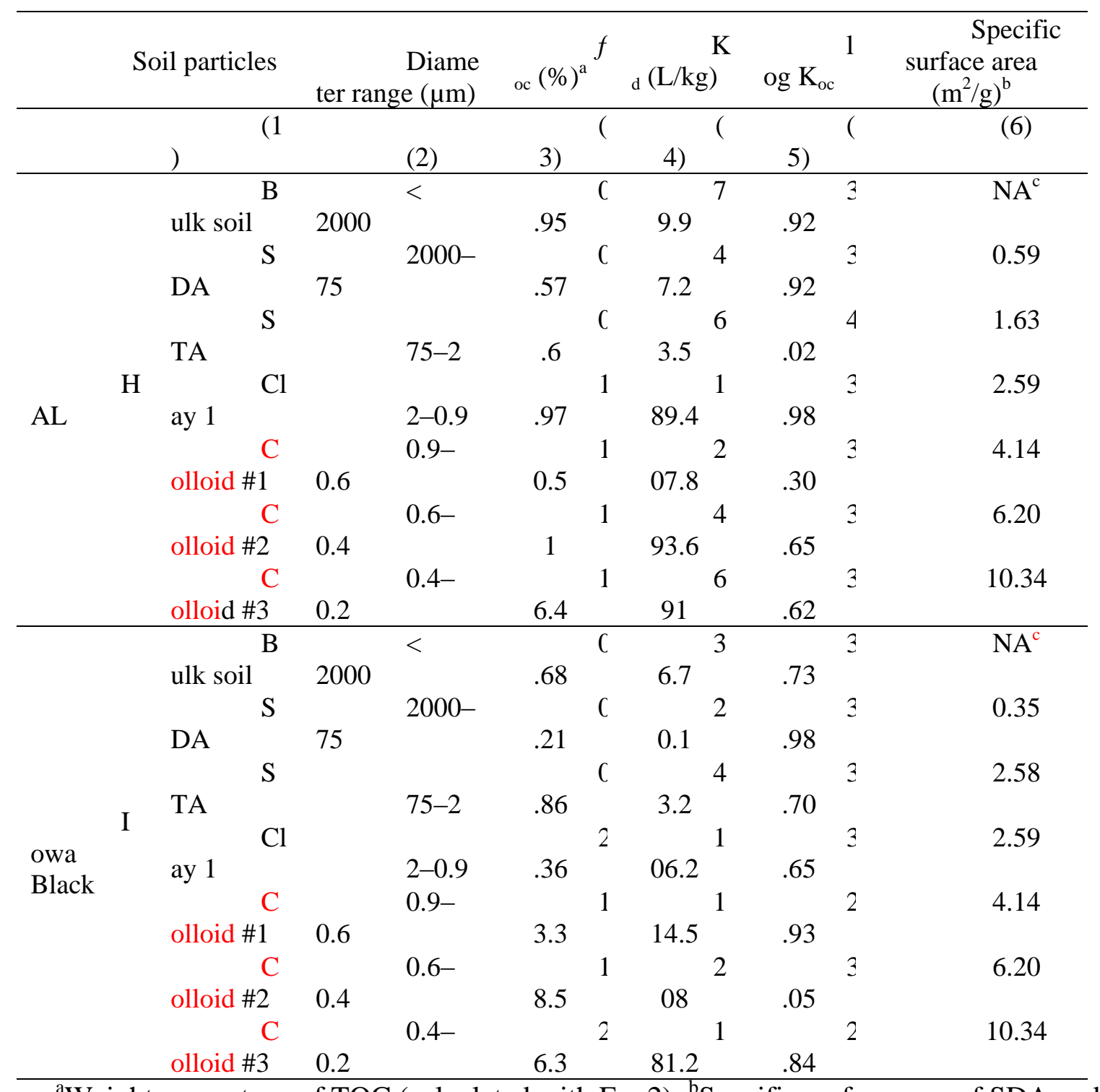

$534 \quad{ }^{a}$ Weight percentage of TOC (calculated with Eq. 2); ${ }^{b}$ Specific surface area of SDA and

535 STA of these two soils was tested by a commercial laboratory (Micrometrics analytical services,

536 Norcross, GA, USA) with multipoint surface are using Nitrogen gas (ISO 9277). ${ }^{\mathrm{N}} \mathrm{NA}=\mathrm{Not}$

537 available

538 
Table 2. Contribution percent of soil particles of each size fraction to the accumulated 540 sorption of particles of all size fractions.

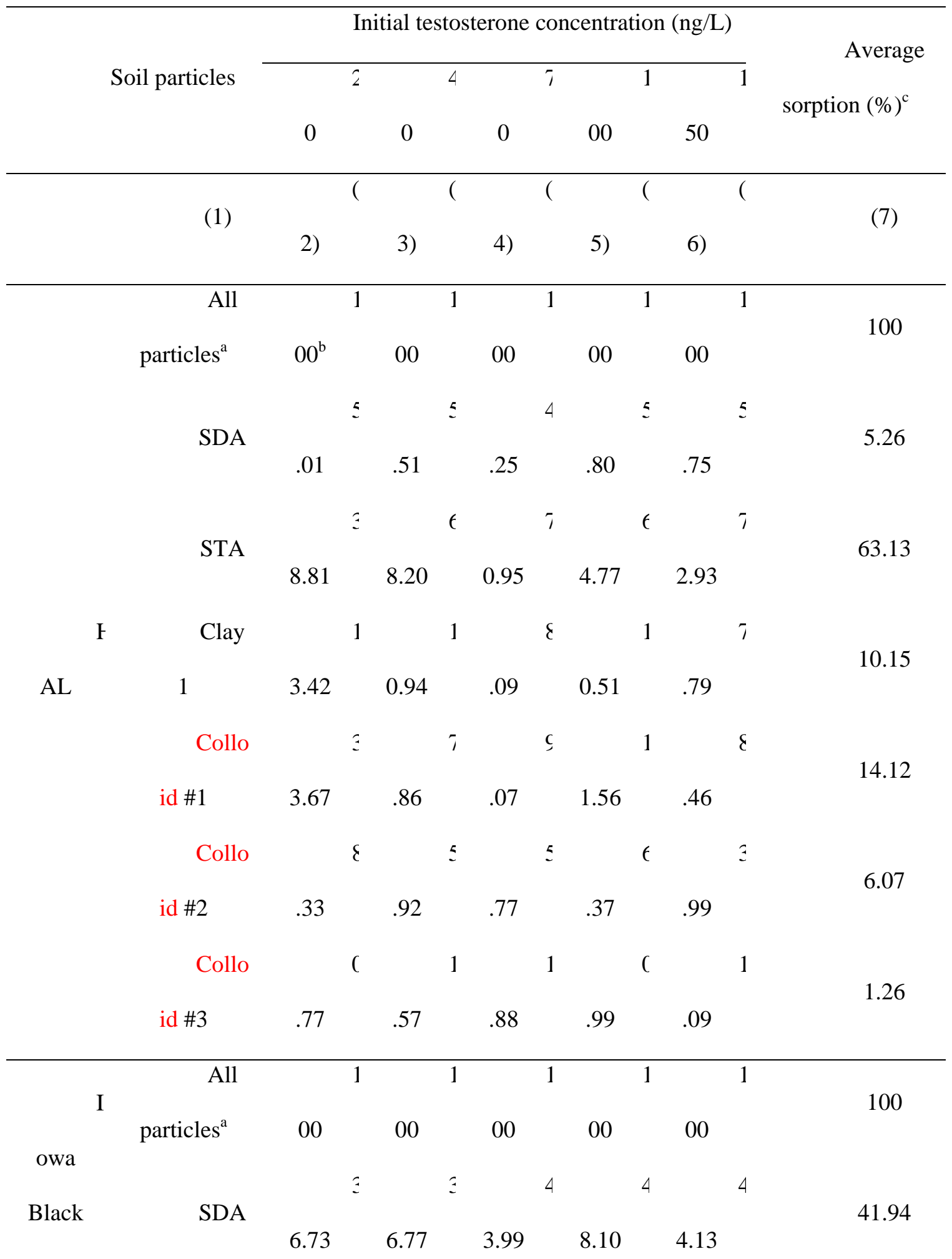




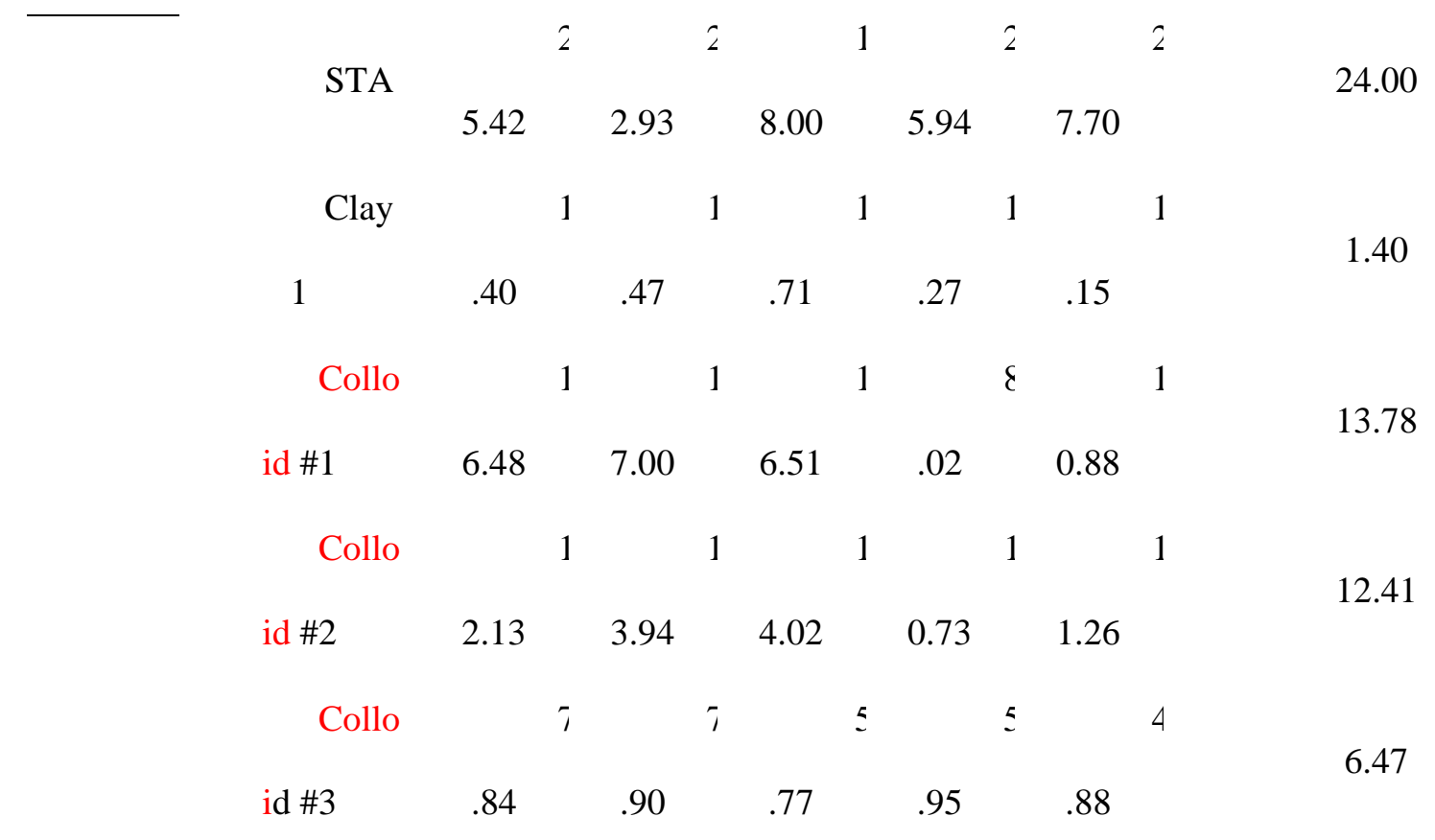

${ }^{\mathrm{a}}$ All particles = SDA + STA + Clay 1+ Colloids \#1, \#2 and \#3 based on data shown in Fig.

$5428 ;{ }^{b}$ The total testosterone sorbed by all of the particles is treated as $100 \% ;{ }^{c}$ Average value of

543 Column (2) to (6).

544 
Table 3. Error caused by using fully-dispersed soil particles and whole soils of HAL as

546 testing materials to predict the transport of testosterone in runoff.

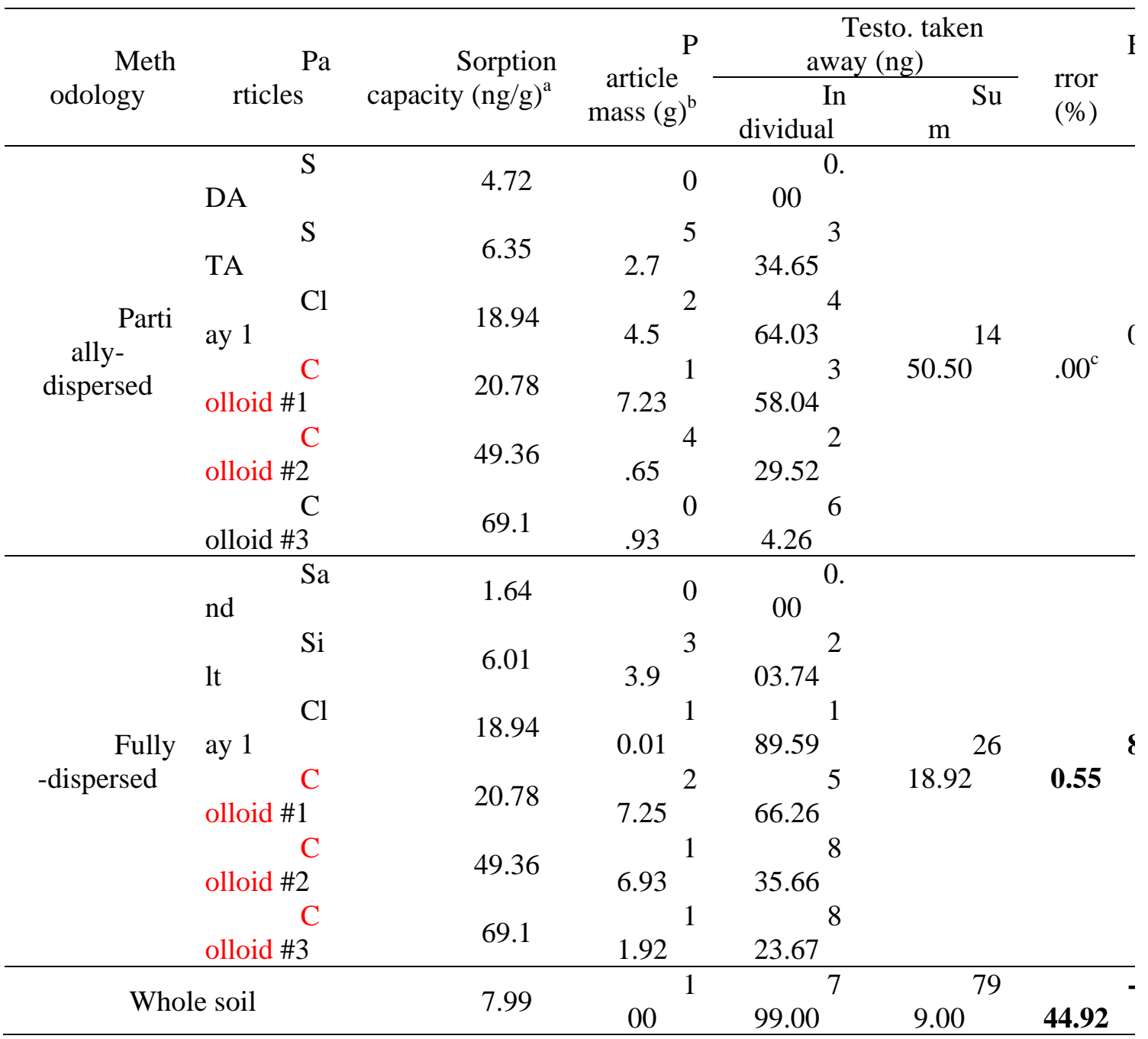

$548100 \mathrm{ng} / \mathrm{L}$; ${ }^{\mathrm{b}}$ Data from Table S1 by assuming the total soil particles taken away by runoff is $100 \mathrm{~g}$;

$549{ }^{c}$ Using the result of partially-dispersed soil particles as the datum for other two estimations. 
Table 4. Particle-based contribution percent to the properties of the "whole" HAL and

552 Iowa Black soils.

\begin{tabular}{|c|c|c|c|c|c|c|}
\hline \multirow{2}{*}{\multicolumn{3}{|c|}{ Soil particles }} & \multirow[b]{2}{*}{ Weight $(g)^{\mathrm{a}}$} & \multirow{2}{*}{$(\%)^{\mathrm{TOC}}$} & \multirow{2}{*}{$\begin{array}{r}\text { Surface } \\
\text { area }(\%)^{c}\end{array}$} & \multirow{2}{*}{$\begin{array}{r}\text { Average } \\
\text { sorption }(\%)^{\mathrm{d}} \\
\end{array}$} \\
\hline & & & & & & \\
\hline & & (1) & (2) & (3) & (4) & (5) \\
\hline \multirow{6}{*}{$\mathrm{AL}$} & \multirow{5}{*}{$\begin{array}{l}\mathrm{d} \# 1 \\
\mathrm{~d} \# 2\end{array}$} & $\mathrm{SDA}$ & 9.1 & 5.2 & 3.25 & 5.26 \\
\hline & & STA & $95^{84 .}$ & 51.0 & 83.53 & 63.13 \\
\hline & & Clay 1 & $2^{2.8}$ & 5.5 & 4.39 & 10.15 \\
\hline & & Colloi & $9^{2.4}$ & 26.1 & 6.19 & 14.12 \\
\hline & & Colloi & $4^{0.5}$ & 5.9 & 2.01 & 6.07 \\
\hline & $\mathrm{d} \# 3$ & Colloi & $0^{0.1}$ & 1.7 & 0.63 & 1.26 \\
\hline \multirow{6}{*}{$\begin{array}{c}\text { owa } \\
\text { Black }\end{array}$} & \multirow[b]{3}{*}{ I } & SDA & $19^{74 .}$ & 13.73 & 24.14 & 41.94 \\
\hline & & STA & $87^{20 .}$ & 15.82 & 50.07 & 24.00 \\
\hline & & Clay 1 & $2^{0.3}$ & 0.67 & 0.77 & 1.40 \\
\hline & $\mathrm{d} \# 1$ & Colloi & $9^{2.2}$ & 26.84 & 8.82 & 13.78 \\
\hline & $\mathrm{d} \# 2$ & Colloi & $1^{1.6}$ & 26.25 & 9.28 & 12.41 \\
\hline & $\mathrm{d} \# 3$ & Colloi & $2^{0.7}$ & 16.69 & 6.92 & 6.47 \\
\hline
\end{tabular}

$553 \quad{ }^{a}$ Data from Fig. 4 for HAL, Fig. 5 for Iowa Black, assuming the "whole" soil is $100 \mathrm{~g}$; ${ }^{\mathrm{b}}=$ $554\{$ [Column (2) x Table 1's Column (3)]/[Total organic carbon $=\Sigma$ [Column (2) x Table 1's 555 Column (3) $]]\} \times 100 \% ;{ }^{c}=\{[$ Column $(2) \times$ Table 1 's Column $(6)] /[$ Total surface area $=\Sigma$ 556 [Column (2) x Table 1's Column (6)] ]\} $\times 100 \%$; 'Data from Table 2's Column (7). 


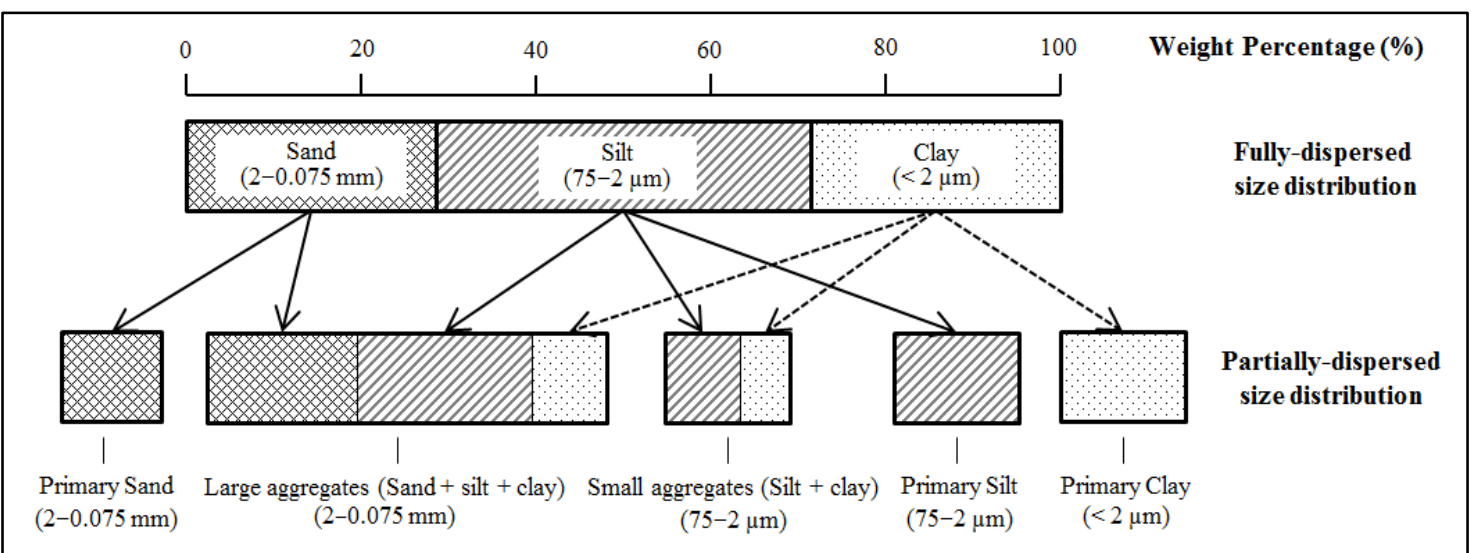

559 Figure 1. Relationship between the fully-dispersed and partially-dispersed soil particle size distribution (Foster et al., 1985; Di Stefano et al., 2002). 


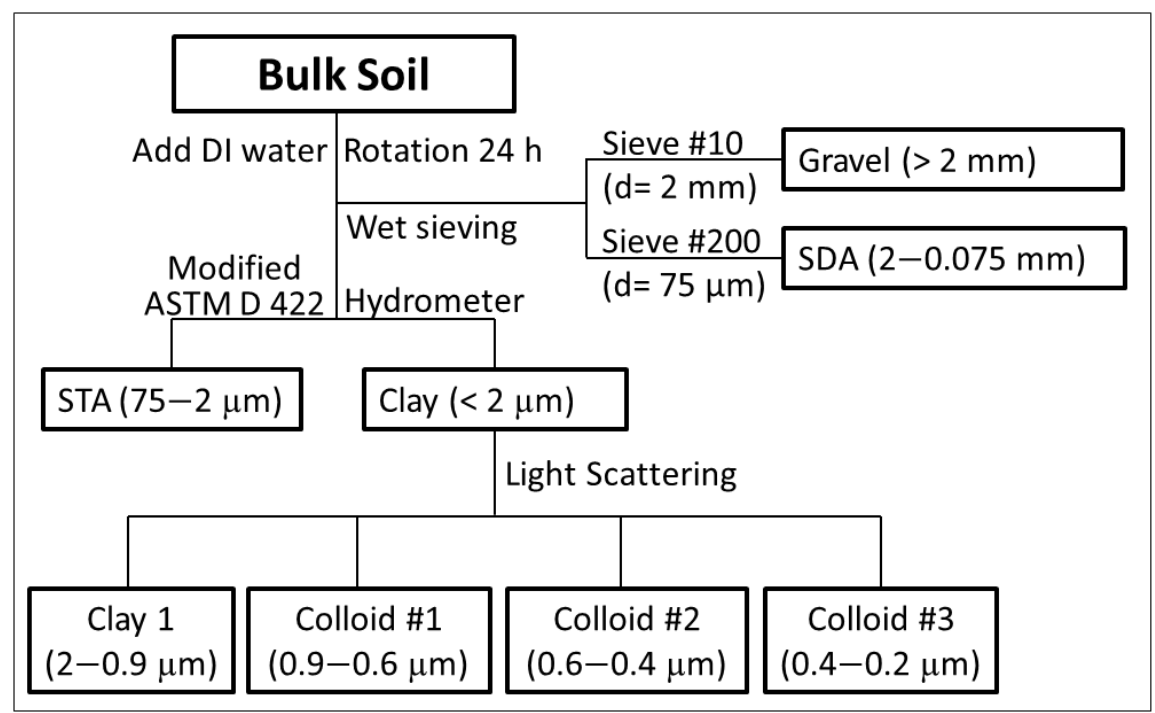

563 Figure 2. Procedures for determining the mass distribution of particle size fractions in the bulk soil, based on ASTM D 422 but without steps: a) adding $\left(\mathrm{NaPO}_{3}\right)_{6}$ or b) high-speed stirring. Steps a) and b) would result in a fully-dispersed size distribution, but soil with a partially-dispersed size distribution is more appropriated for F/T studies (Table 4). SDA $=$ primary sand and large aggregates $;$ STA $=$ primary silt and small aggregates (see Fig. 1 for definitions). 


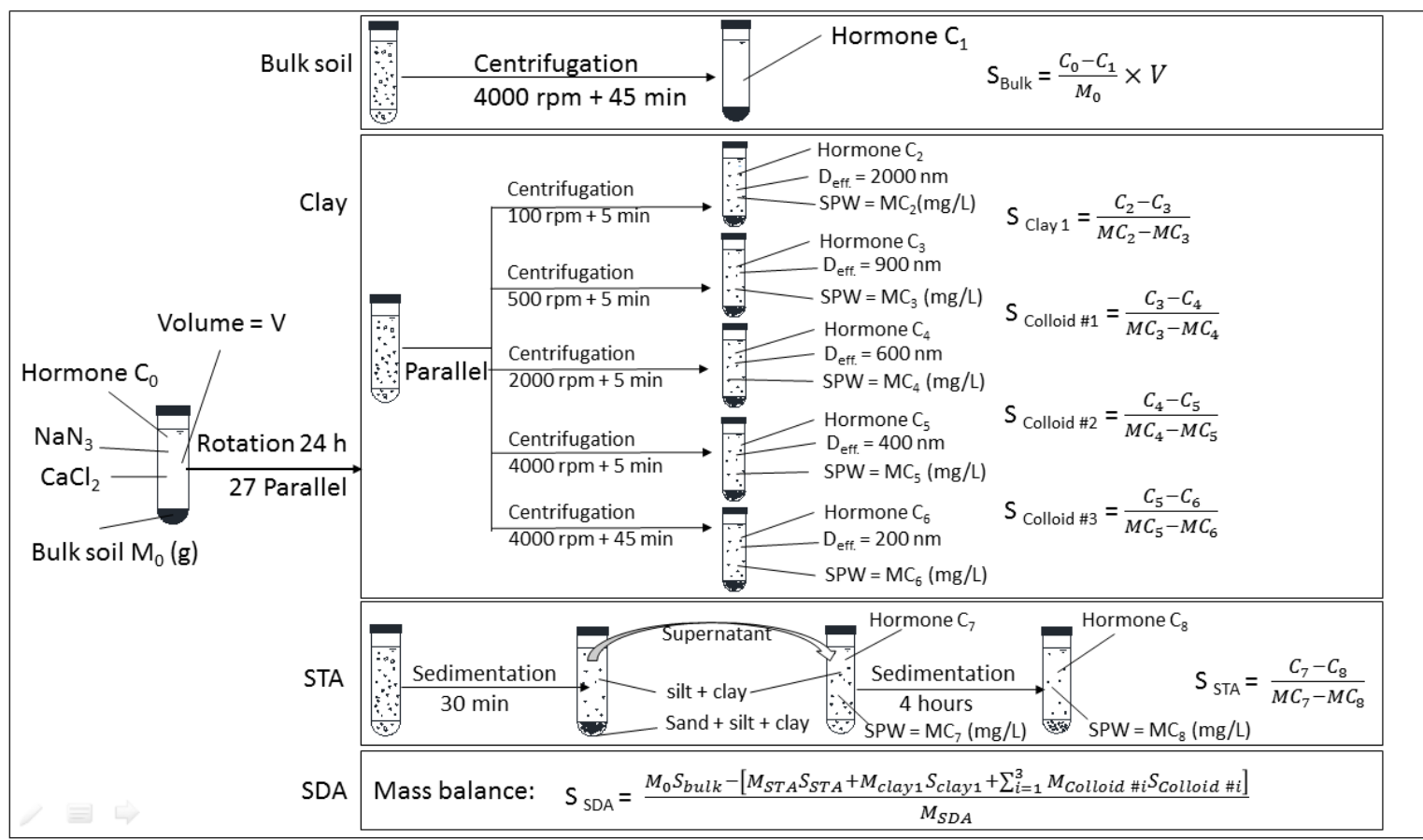

571 Figure 3. Procedures for conducting sorption tests collectively (with the bulk soil) and then determining individually the hormone sorption to the particles of different size fractions. Other parameters (e.g., $f_{\text {oc }}$ ) of different size fractions can be determined by the same method as long as $\mathrm{C}_{\mathrm{i}}$ can be detected. Here, we assume solids (diameter < $200 \mathrm{~nm}$ ) in the supernatant after centrifugation at $4000 \mathrm{rpm}$ for 45 minutes to be in the dissolved phase. The units of the equations must be adjusted accordingly. SPW $=$ soil particle weight; $D_{\text {eff. }}=$ effective diameter; STA, SDA are shown in Fig. 2 . The tests were conducted with triplicated and three blanks, total 27 parallel samples. 

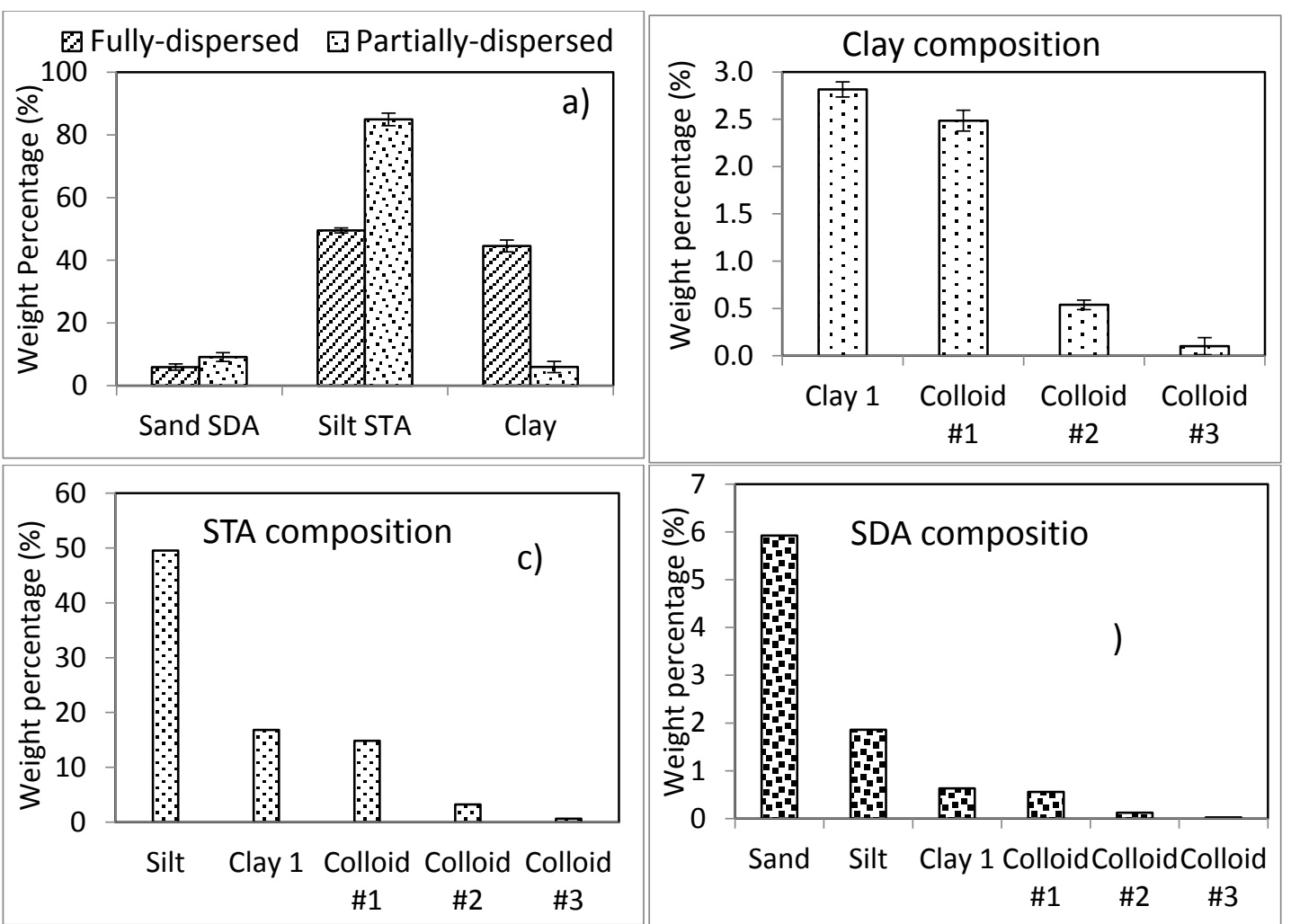

583 Figure 4. Fully-dispersed and partially-dispersed particle size distribution of HAL soil. Error bars indicate the standard deviation of duplicated results. 

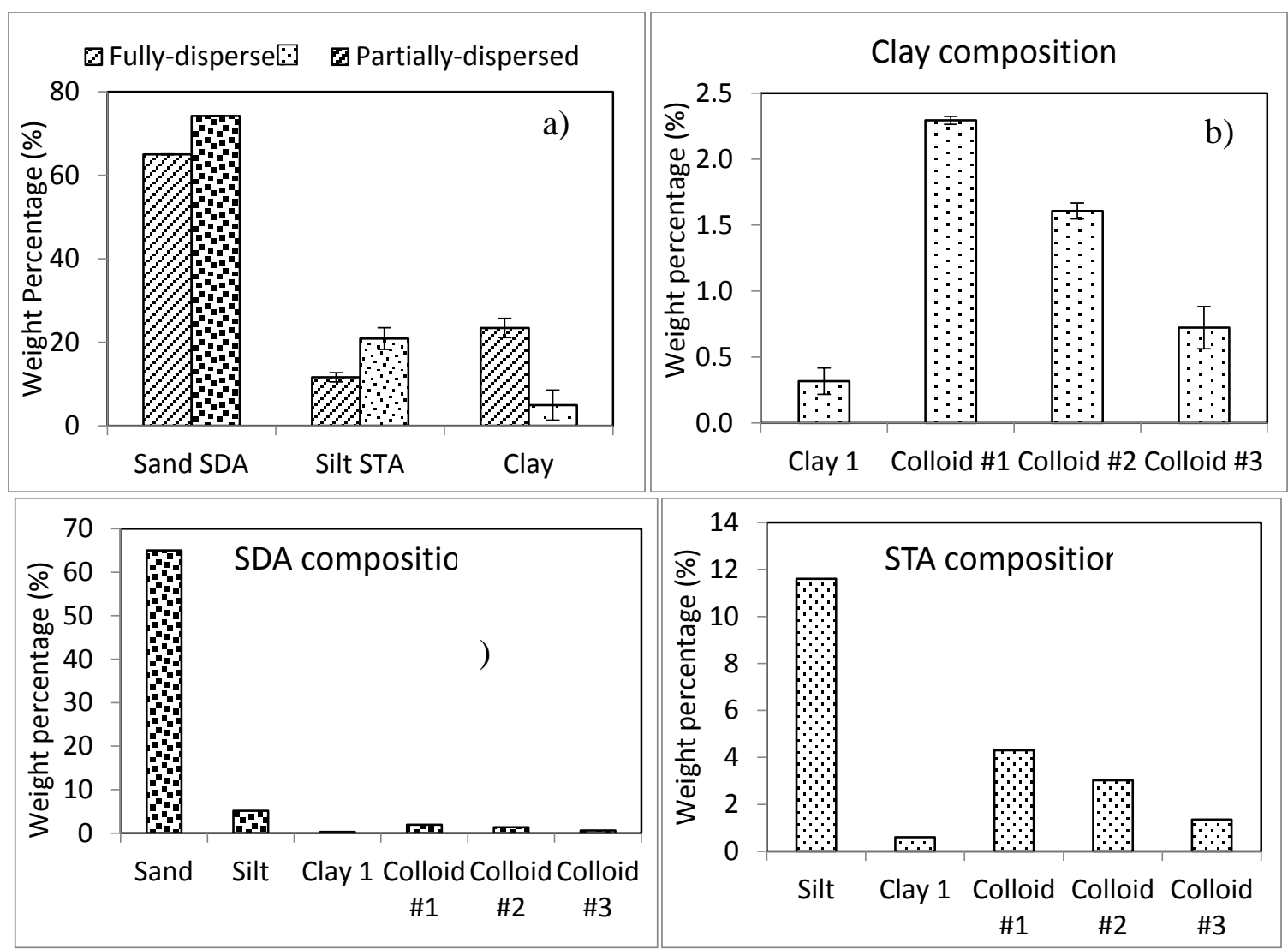

590 Figure 5. Fully-dispersed and partially-dispersed particle size distribution of Iowa Black soils.

$591 \quad$ Error bars indicate the standard deviation of duplicated results.

592 


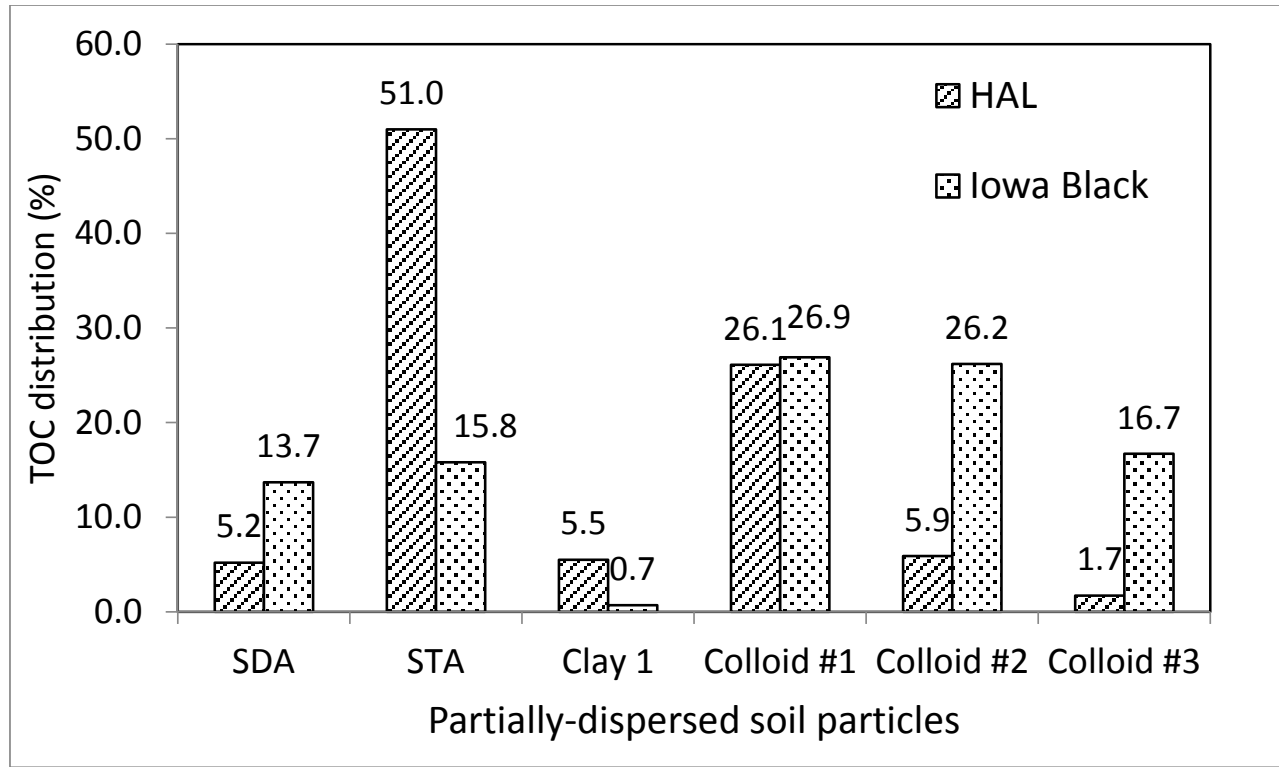

594 Figure 6. TOC distribution (\%) among partially-dispersed soil particles of six DSFs of HAL and 595 Iowa Black soils.

596

597

598 

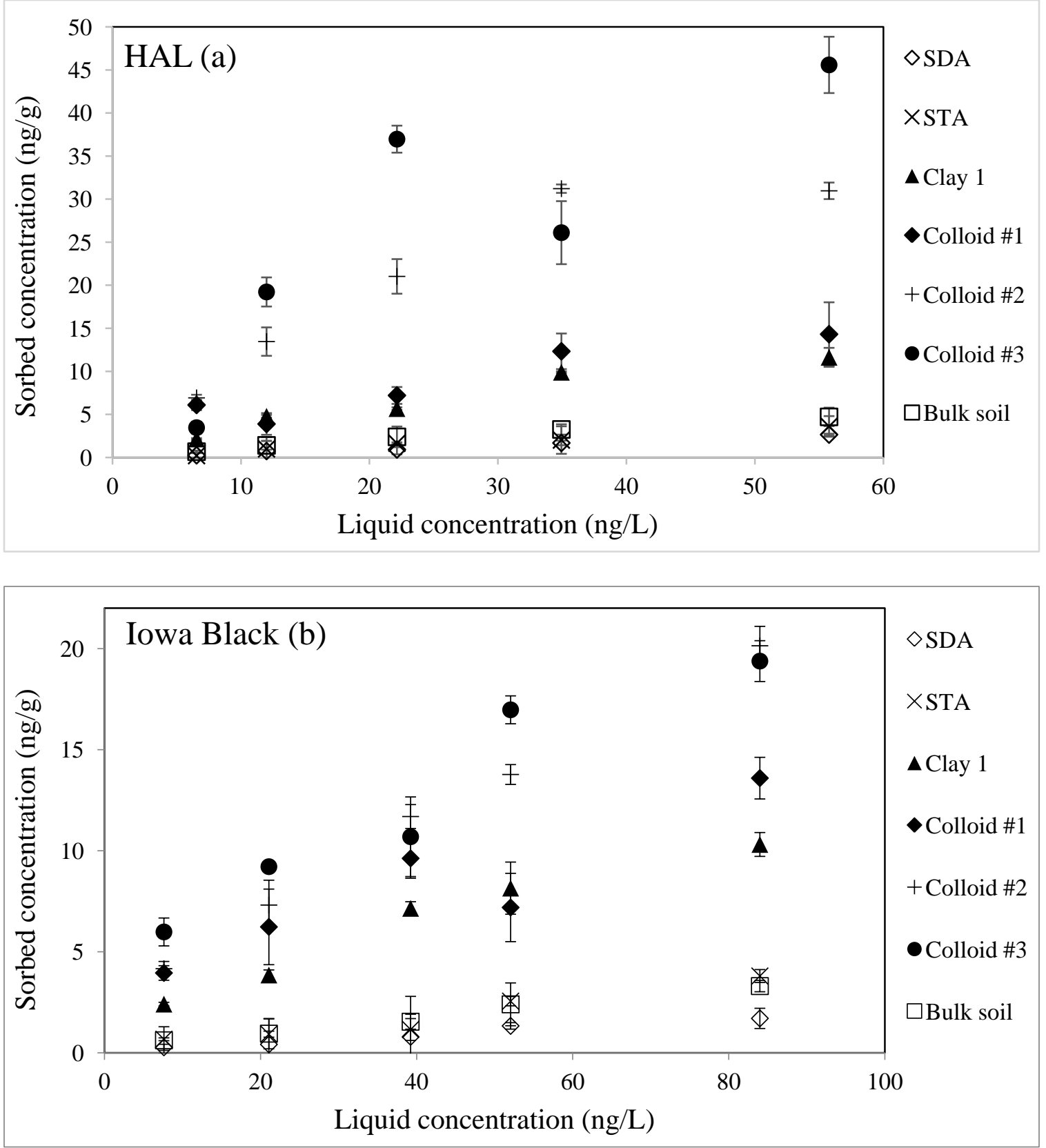

601 Figure 7. Sorption isotherm of HAL and Iowa Black bulk soils and their partially-dispersed soil

602 particles of six DSFs on testosterone at the initial testosterone concentration of 20-150

603 ng/L. Error bars indicate the standard deviation of triplicated results.

604 


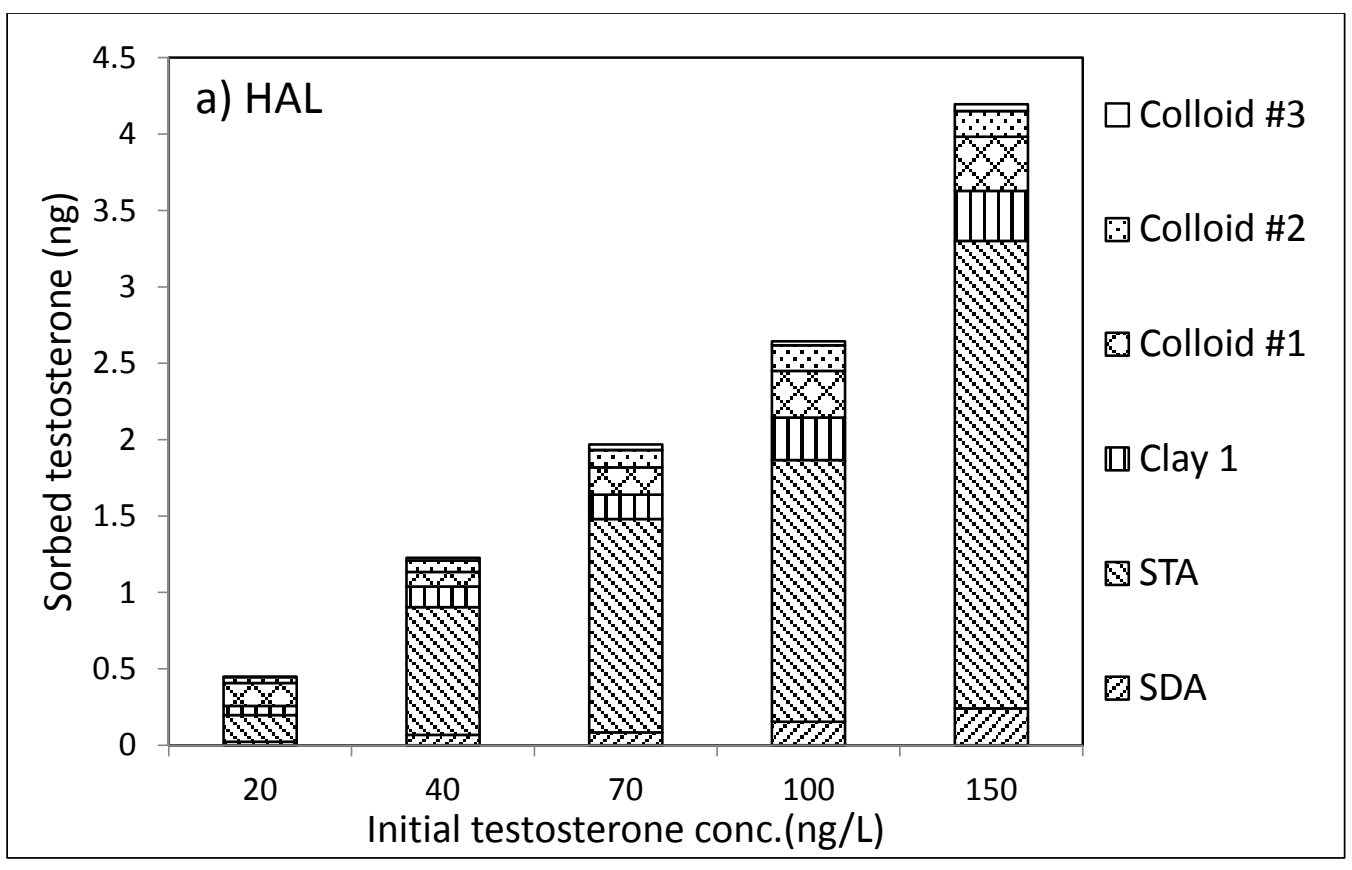

606

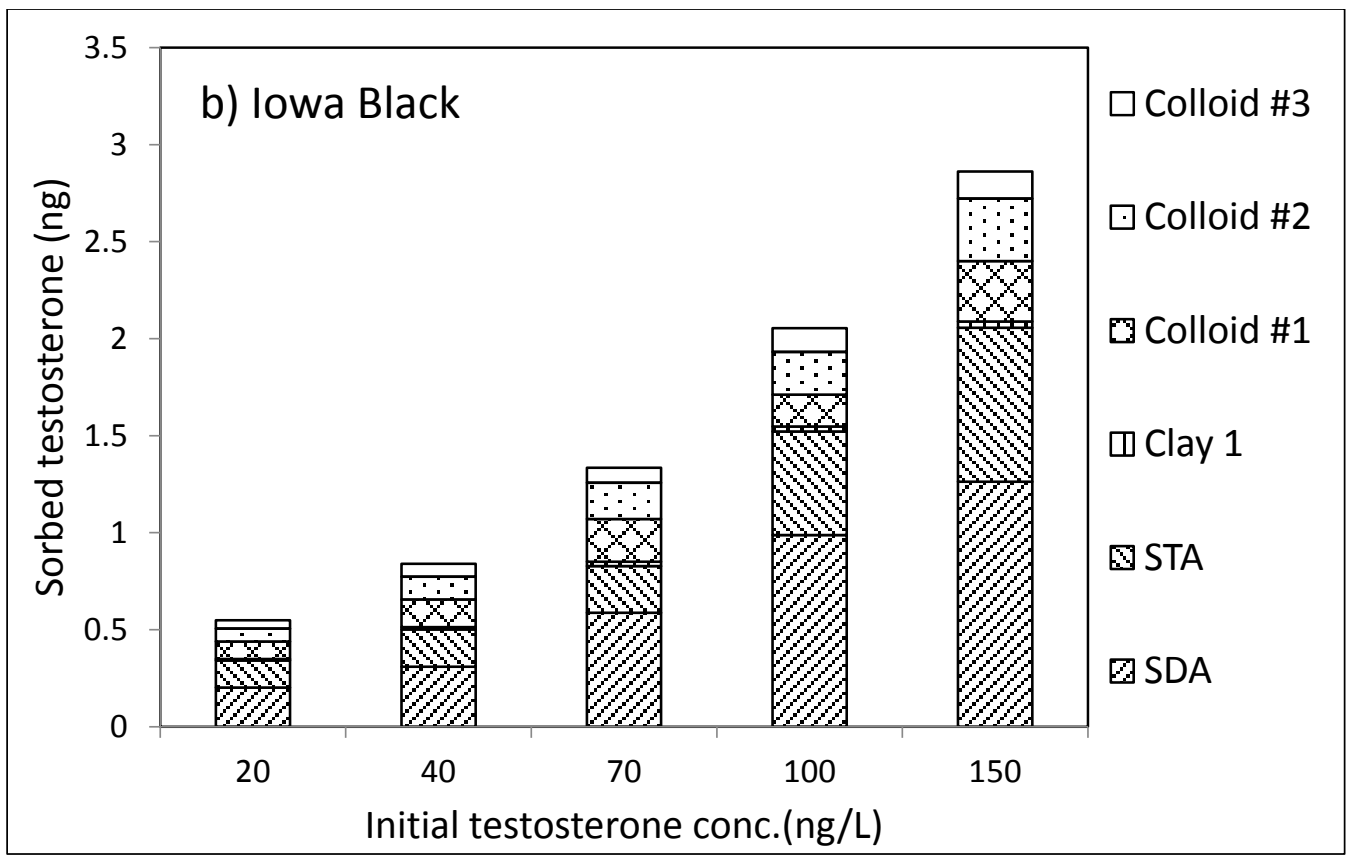

607 Figure 8. Sorption mass distribution of testosterone to soil particles of six DSFs of HAL (a) and Iowa Black (b) at the initial testosterone concentration of 20-150 ng/L. Data from Figs.

609 $4,5 \& 7$. 
612

613

614

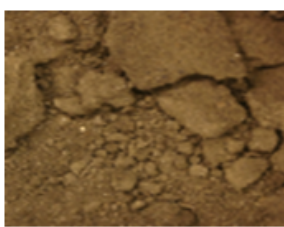

Bulk soil
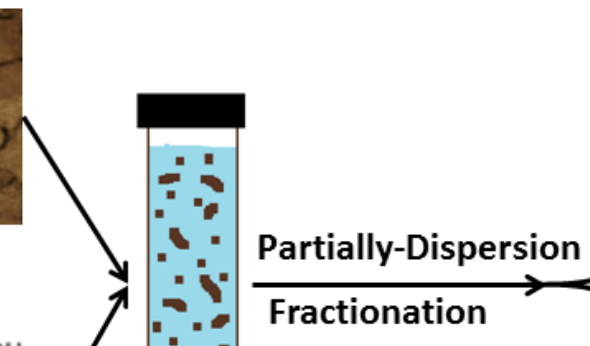

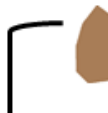
$0.427-0.075 \mathrm{~mm}$

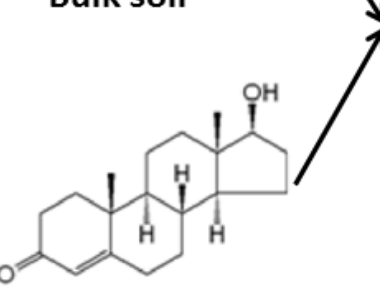

Testosterone

Sorption

$0.075-2 \mathrm{~mm} \longrightarrow \quad$ Sorption Distribution

615 